\title{
O ser que envelhece: técnica, ciência e saber
}

\section{The being that ages: technique, science and knowledge}

Shirley Donizete Prado ${ }^{1}$ Jane Dutra Sayd ${ }^{2}$
${ }^{1}$ D epartamento deN utrição Social, I nstituto deN utrição, UERJ. Rua São Francisco Xavier, 524, $12^{\circ}$ andar, Bloco D, Pavilhão J oão Lyra Filho, M aracanã. 20559-900 Rio deJaneiro RJ

shirley_prado@terra.com.br ${ }^{2}$ Departamento de Planejamento e

Administração em Saúde do Instituto de M edicina Social daUERJ.
Abstract We address Gerontology in its perception as the science of aging. Based on Bachelard and Canguilhem, we discuss the perspectives of Gerontology as science in terms of A ging Philosophy, Aging Genetics or Bio-Gerontology, and as a set of techniques for cure such as pain relief, action on life of the being that ages through Geriatrics, Psycho-geriatrics, Geriatric Nursing and Social Service. Based on Foucault, we consider that Gerontology comprisesall knowledge on that uniquebeing who thinksabout himself and about his own representations, through Anthropology, Psychoanalysis, and so on. As to the fact that aging is the object, we see this as an ambitious project, which almost coincides with H uman Sciences and Life when these deal with youth and old age. Gerontology is today a set of sciences, techniques and knowledge, mainly concerned with the still indefinite domain of old age.

Key words Aging, Research, Tendencies, Gerontology
Resumo Abordamosa Gerontologia, que se pre tende ciência do envelhecimento. A partir de Bachelard e Canguilhem, discutimos as perspectivas da Gerontologia como ciência naquilo que se refere à Fisiologia do Envelhecimento, da Genética do Envelhecimento ou da Biogerontologia e como um conjunto de técnicas de cura, de alívio da dor, de ação sobre a vida do ser que envelhece através da Geriatria, da Psicogeriatria, da Enfermagem Geriátrica, do Serviço Social, por exemplo. A partir do pensamento de Foucault, consideramosque a Gerontologia inclui os saberes sobreesteser único que pensa sobre si mesmo e sobre suas próprias representações por meio da Antropologia, da Psicanálise, entre outras. Quanto a ter por objeto 0 envelhecimento, entendemos que se trata de um projeto absolutamente ambicioso, que praticamente coincide com as Ciências Humanas e da $V$ ida quando tematizam a juventude e o envelhecer. Hoje, parece-nos, a Gerontologia corresponde a um conjunto de ciências, técnicas e saberes voltados, principalmente, para esse ainda nebuloso domínio que é a velhice. Palavras-chave Envelhecimento, Pesquisa, Tendências, Gerontologia 
Introdução

A ciência ocupa lugar privilegiado no mundo moderno. Seu desenvolvimento, em particular no que se refere aos aspectos tecnológicos, coloca-a em posição de destaque por conta do estatuto de verdade que confere às conclusões sobre os mais diversos fenômenos que aborda. Outrora esse valor de verdadejá foi estabelecido predominantemente pela magia e/ou pela religião, por exemplo. Hoje, toda a infra-estrutura institucional que cerca al guns campos como a física, por exemplo, toma caráter de grandioso poder, que envolve a produção de conhecimentos e os aparatos técnicos, os equipamentos, os procedimentos, importando investimentos e realizações espetaculares, de grande visibilidade e credibilidade. Tudo isso vem caracterizando a al egação da ciência como detentora de enormes poderes. Stengers ${ }^{1}$ nos alerta para os perigos de leituras que a tomam integralmente identificada com um projeto oculto de dominação do mundo e nos convida a aprofundar a singularidade de cada uma de suas manifestações e a especificidade de cada campo científico na construção de poderes diversos, grandes ou pequenos, enganadores ou verdadeiros.

N um cenário contemporâneo em quediscursos especializados brotam em intensa multiplicação², a busca por sua legitimação como campos da ciência é intensa. No caso da Gerontologia brasileira, tal processo fica bem evidenciado no trabal ho de Lopes ${ }^{3}$ sobre a trajetória da Sociedade Brasileira de Geriatria e Gerontologia (SBGG) em sua busca de estabelecer-se como autoridade cientifica, o que se dá de forma particularmente intensificada de 1990 até os dias atuais. Essa tendência, parece-nos, perdurará ainda por décadas. Procurando combinar discurso científico e defesa dos idosos, a Geriatria e a Ge rontologia vêm crescendo no mercado de trabaIho, firmando-se como autoridade no estabele cimento de normas e condutas na velhice.

0 investimento em esforços que conduzam à constituição de bases teóricas que permitam afirmar o caráter científico de determinado discurso especializado também corresponde à estratégia para legitimação de novos campos que tratam de ser reconhecidos como ciência. Stengers assinala a existência de movimentos que buscam na epistemologia, no atendimento a critérios epistemológicos, as referências para seja possível afirmar que tal ou qual prática seja científica.

No campo do envelhecimento, Sá 5 propõe referências epistemológicas, buscando estabelecer a que tipo de ciência corresponde a Geronto- logia, se formal ou se técnica, e que teorias e metodologias a sustentariam.

Temos, portanto, que são bem claras as iniciativas dirigidas a consolidar argumentos em favor da Gerontologia como campo da ciência; seja por meio de uma entidade de classe - a SBGG, que investena aproximação com a universidade, espaço reconhecido por excelência como de produção de conhecimento científico - , seja através da construção de uma fundamentação teórica apoiada numa epistemologia que apresenta a Gerontologia como uma ciência técnica, tal qual a M edicina ou a Arquitetura ou o Serviço Social, eque devevoltar-se deforma enfática para a ação, para a intervenção.

\section{Gerontologia. Ciência etécnica.}

A Epistemologia de Gaston Bachelard - em seus estudos que percorrem os campos das "ciências da natureza ou da matéria": a Física e a Química - busca constituir reflexões sobre a produção de conhecimento científico dentro da perspectiva de analisar sua cientificidade. Para tanto, el egea história como instrumento privilegiado de análise, buscando o estabelecimento da historicidade própria de cada região da ciência. E situa-se numa perspectiva filosófica, pois vêna análise histórica de cada campo da ciência a colocação de uma questão fundamental para a Filosofia: a questão da racionalidade científica; conforme M achado ${ }^{6}$, exige uma criticidade que confere à história das ciências sua dimensão filosófica ao

analisar a superação de obstáculos, o desaparecimento dos preconceitos, 0 abandono dos mitos, 0 que torna possível o progressivo acesso à racionalidade; ela é um instrumento filosófico de clarificação do conhecimento que tem como norma a própria racionalidade científica em seu mais elevado grau de elaboração. A epistemologia é, portanto, uma filosofia que tematiza a questão da racionalidade através da ciência, por ela considerada como atividade racionalista por excelência.

Georges Canguilhem ${ }^{7}$, utilizando a estrutura metodológica que identifica a epistemologia bachelardiana, volta-se para a análise das "ciências da vida" - Biologia, Fisiologia - a partir da discussão dos conceitos de normal e de patológico.

A Fisiologia é tratada de forma distinta da M edicina no que se refere ao estabelecimento do que seja científico, da total aplicabilidade de procedimentos científicos como características desses campos. A Fisiologia é uma ciência "autenticamente por sua procura de constantes e de inva- 
riantes, por seus processos métricos, por sua atitude analítica geral" e seu objeto "os ritmos estabilizados da vida". A Fisiologia, em seus pensamentos, correspondea uma certa derivação da M edicina, clínica e terapêutica, construída a partir do sofrimento, da doença de um ser, de obstáculos patológicos.

[...] é o pathos que condiciona o logos porque é ele que o chama. É 0 anormal que desperta 0 interesse teórico pelo normal. As normas só são reconhecidas como tal nas infrações. As funções só são reveladas por suas falhas. A vida só se eleva à consciência eà ciência desi mesma pela inadaptação, pelo fracasso, pela dor (grifos do autor).

Assim, a Medicina encontra-se situada em outro campo que não o da ciência, mas 0 das técnicas de alívio do sofrimento, da cura, um campo de subjetividades, de valores, de construção incessante de novas normalidades.

Em matéria de patologia, a primeira palavra, historicamentefalando, ea última palavra, logicamente falando, cabem à clínica. O ra, a clínica não é uma ciência e jamais o será, mesmo que utilize meios cuja eficácia seja cada vez mais garantida cientificamente. A clínica é inseparável da terapêutica, ea terapêutica éuma técnica de instauração e restauração no normal, cujo fim escapa do saber objetivo, pois é a satisfação subjetiva de saber que uma norma está instaurada. Não se ditam normas à vida, cientificamente. $M$ as a vida éessa atividade polarizada de conflito com o meio, eque se sente ou não normal, conforme se sinta ou não em posição normativa. 0 médico optou pela vida. A ciência lhe é útil no cumprimento dos deveres decorrentes dessa escolha. 0 apelo ao médico parte do doente. É o caso desse apelo patético que faz chamar de patológicas todas as ciências que a técnica médica utiliza em socorro da vida. [...] Sua qualidade de patológica, porém é uma noção de origem técnica e, por isso, de origem subjetiva. Não há patologia objetiva. Pode-se descrever objetivamente estruturas ou comportamentos, masnão se pode chamá- los de "patológicos" com base em nenhum critério puramente objetivo. Objetivamente, só se pode definir variedades ou diferenças, sem valor vital positivo ou negativo (grifos do autor).

Conforme assinalamos em estudos anteriores ${ }^{8,9,10}$, entre os grupos de pesquisa que se voltam para questões relativas a envelhecimento há, no Brasil, larga predominância daqueles situados no campo das Ciências da Vida (Tabela 1), com especial destaque para as Ciências da Saúde, e, em seu interior, para a M edicina, a Saúde Coletiva, a Enfermagem. Se considerarmos, por hipótese, que esse perfil mantém correspondência com o conjunto das atividades desenvolvidas em Gerontologia, de um modo geral, teremos que esta se caracteriza por um predomínio das atividades profissionais situadas no campo da saúde.

Daí, se tomarmos as referências da Epistemologia de Bachelard e de Canguilhem, teremos

Tabela 1

Grupos de pesquisa que contam com linhas de pesquisa referentes ao envelhecimento humano por Grande Área predominante. Brasil, 2000.

\begin{tabular}{|c|c|c|c|c|c|c|}
\hline \multirow[t]{3}{*}{ Grande área predominante } & \multicolumn{6}{|c|}{$\begin{array}{l}\text { Grupos de pesquisa com linhas de pesquisa } \\
\text { referentes ao envelhecimento humano }\end{array}$} \\
\hline & \multicolumn{2}{|c|}{ Específicos* } & \multicolumn{2}{|c|}{ Não específicos** } & \multicolumn{2}{|c|}{ Total } \\
\hline & $\mathrm{N}$ & $\%$ & $\mathrm{~N}$ & $\%$ & $\mathrm{~N}$ & $\%$ \\
\hline Ciências da Saúde & 26 & 60,5 & 56 & 55,4 & 82 & 56,9 \\
\hline Ciências Biológicas & 8 & 18,6 & 17 & 16,8 & 25 & 17,4 \\
\hline Ciências Humanas & 4 & 9,3 & 16 & 15,8 & 20 & 13,9 \\
\hline Ciências Sociais Aplicadas & 4 & 9,3 & 10 & 9,9 & 14 & 9,7 \\
\hline Ciências Exatas e da Terra & 0 & 0,0 & 1 & 1,0 & 1 & 0,7 \\
\hline Engenharias & 0 & 0,0 & 1 & 1,0 & 1 & 0,7 \\
\hline Lingüística, Artes e Letras & 1 & 2,3 & 0 & 0,0 & 1 & 0,7 \\
\hline Total & 43 & 100,0 & 101 & 100,0 & 144 & 100,0 \\
\hline
\end{tabular}

Fonte: Prado et al. ${ }^{10}$

(*) Grupos em quetodas as linhas de pesquisa estão voltadas para o envelhecimento humano.

(**) Grupos em quealguma(s) linha(s) de pesquisa está(ão) voltada(s) para o envelhecimento humano. 
que a M edicina, voltada para a pessoa idosa com a perspectiva da cura - a Geriatria, a Psicogeriatria etc. - , como também todas aquelas atividades profissionais que têm por objetivo o cuidado, a atenção para com a saúde, a ação sobre a vida dos velhos - a Enfermagem Geriátrica, a Nutrição Geriátrica, a O dontogeriatria etc. -, devem ser tratadas de forma distinta daqueles campos de produção de conhecimentos científicos, como a Fisiologia do Envelhecimento ou a Genética do Envelhecimento, ou a Biologia do Envelhecimento, quebuscam conhecer o processo de envelhecimento humano em suas constantes, suas invariantes, via procedimentos analíticos. Observa-se largo predomínio das atividades de natureza técnica sobre as de cunho científico nesse espaço geronto-geriátrico.

Então, tomando não mais a Gerontologia como um todo, mas apenas os grupos de pesquisa com o propósito declarado de produzir conhecimento sobre questões afins ao envelhecimento e saúde, aí sim, caberia uma abordagem epistemológica, uma reflexão histórico-filosófica, uma análise da cientificidade de seus procedimentos. Isto exige o exame profundo dos conceitos- elemento privilegiado quemelhor exprimea racionalidade científica - devel hicee de envel he cimento, problemática que, como discutimos também em nossos estudos anteriores, vem sendo abordada de modo frágil, ao menos no cenário nacional.

\section{Gerontologia. Ciência esaber.}

Construindo um certo deslocamento em relação à Epistemologia, encontramos, em Michel Foucault ${ }^{11}$, a Arqueologia do Saber, cujas análises estão centradas na questão do homem, na constituição histórica das "ciências do homem" na modernidade: uma nova região ao lado das regiões "da natureza" e "da vida". Trata-se de uma nova abordagem analítica que guarda em comum com a Epistemologia a exigência de realizar uma análise conceitual profunda equetem a Filosofia ea História como elementos-chave para seu desenvolvimento, mas que se distingue pelo abandono à questão da cientificidade, cerne do projeto epistemológico. As palavras sintéticas de $\mathrm{M} \mathrm{a-}$ chado ${ }^{6}$ são esclarecedoras em relação a essas distinções:

Parece nos mesmo que a riqueza do método arqueológico é ser um instrumento capaz de refletir sobre as ciências do homem enquanto saberes investigando suas condições de existência através da análise do que dizem, como dizem e porque dizem - neutralizando a questão da cientificidade e escapando assim ao desafio impossível da recorrência, sem, no entanto, abandonar a exigência de realizar uma análise conceitual capaz de estabelecer descontinuidades, não certamente epistemológicas, mas arqueológicas, isto é, situadas ao nível dos saberes.

Essencialmente, o trabalho deFoucault implica um deslocamento metodológico da Epistemologia para a Arqueologia, que coloca, em lugar do conhecimento, um novo objeto, o saber. Enquanto que as análises epistemológicas não são aplicáveis para formações discursivas não científicas, a Arqueologia é tomada para dar conta de disciplinas (formações discursivas) não propriamente científicas, o que se dá por meio da análise da positividade do que foi efetivamente dito. Enquanto quea positividadeem epistemologia mantém correspondência com a cientificidade, em arqueologia ela é capaz de caracterizar eindividual izar um discurso como saber, como portador de verdade. $N$ as palavras de M achado ${ }^{6}$ :

A epistemologia subordina a verdade à ciência. A ciência é o lugar específico da verdade no sentido em que ela não tem que se adequar a uma verdade que lhe seria anterior, pois só seus procedimentos são capazes de produzi-la; a questão da verdade se reduz à dos critérios do conhecimento verdadeiro, critérios esses definidos pela ciência em sua atualidade. A arqueologia desloca radicalmente essa problemática. Privilegiando em sua análise não mais a ciência, mas o saber, a história arqueológica também neutraliza a questão da verdade. Ou melhor, desvincula a reflexão histórico-filosófica sobre a verdade da ciência e sua atualidade, eliminando a utilização de qualquer critério externo de verdade para julgar o que é dito nos discursos. A arqueologia aceita a verdade como uma configuração histórica e examina seu modo de produção unicamente a partir das normas internas dos saberes de determinada época.

Por meio da análise arqueológica, Foucault discute o estatuto desse conjunto de discursos sobre o homem constituído no pensamento moderno - as "Ciências Humanas" - abordando a constituição da Biologia, da Economia, da Lingüística, da Sociologia, da Psicologia, da Antropologia, da Psicanálise e da Etnologia, num complexo movimento de redistribuição geral da epistémê, em que, pela primeira vez, seres humanos se tornaram objetos da ciência. Nas palavras de Foucault ${ }^{11}$, "um acontecimento da ordem do saber [...] um dos mais decisivos progressos realizados, na história da cultura européia, pela racio- 
nalidade empírica." 0 resultado dessa reorganização foi expresso na forma do Triedro dos Saberes, conforme discutimos em estudos imple mentados anteriormente ${ }^{12}$.

N essa concepção, o homem, o ser humano individual ou em grupo, escapa à objetividade do conhecimento, transbordando para o campo da positividade do saber dada, não apenas, a sua imensa complexidade como objeto de estudo científico ou a impossibilidade de sua matematização, mas, essencialmente, a sua condição de representar empiricidades e de poder pensar sobre essas suas próprias representações conscientesou inconscientes. $\mathrm{Ou}$, como nos diz Foucault ${ }^{11}$ :

Elas [as ciências humanas] desenham quando se Ihes faz a análise arqueológica, configurações perfeitamente positivas; mas desde que se determinam essas configurações e a maneira como estão dispostas na epistémê moderna, compreende-se porque não podem ser ciências: o que as torna possíveis, com efeito,, é uma certa situação de 'vizinhança' em relação à biologia, à economia, à filologia (ou à lingüística); elas só existem na medida em quesealojam ao lado destas- ou antes, debaixo delas, no espaço desua projeção. Com elasmantêm, entretanto, uma relação que é radicalmente diferente daquela que se pode estabelecer entre duas ciências 'conexas' ou 'afins': essa relação, com efeito, supõe a transferência de modelos exteriores na dimensão do inconsciente e da consciência e o re fluxo da reflexão crítica em direção ao próprio lugar donde vêm esses modelos. I nútil pois, dizer que as 'ciências humanas' são falsas ciências; simplesmente não são ciências; a configuração que define sua positividade e as enraíza na epistémêmoderna coloca-as, ao mesmo tempo, fora da situação de serem ciências; e se se perguntar então porque assumiram esse título, bastará lembrar que pertence à definição arqueológica de seu enraizamento 0 fato de que elas requerem e acol hem a transferência de model os tomados de empréstimo a ciências. Não é, pois, a irredutibilidade do homem, aquilo que se designa como sua invencível transcendência, nem mesmo sua complexidade demasiado grande que $\mathrm{O}$ impede de tornar-se objeto de ciência. A cultura ocidental constituiu, sob o nome de homem, um ser que, por um único e mesmo jogo de razões, deve ser domínio do saber e não pode ser objeto de ciência (grifos do autor).

N ossos estudos indicam que entre os grupos de pesquisa brasileiros que contam com linhas de pesquisa voltadas em algum grau para o ser humano em seu envel hecer predominam aqueles situados no campo das Ciências da Vida (Saúde eBiológicas); em seguida, vêm os que se identifi- cam com as chamadas Ciências Humanas, com destaque para a Psicologia, o Serviço Social, a Sociologia, a Antropologia. Projetamos composição similar para a Gerontologia, em sua concepção mais geral, incluindo atividades profissionais (denaturezatécnica) voltadas centralmente para o cuidado, para a atenção, para a ação sobre a vida das pessoas idosas - como o Serviço Social, por exemplo.

Da mesma forma, considerando não mais a Gerontologia como um todo, mas apenas os grupos de pesquisa, caberiam aí abordagens epistemológica e arqueológica, reflexões histórico-fiIosóficas, análises da cientificidade e da positividade na produção desses conhecimentos e saberes. Permanecendo a exigência do exame profundo dos conceitos de vel hice e de envelhecimento nos campos do Serviço Social, da Psicologia etc.

A partir desse tratamento mais ampliado, ou seja, da consideração de referências teóricas mais abrangentes, poderemos partir para análises mais profundas e, inclusive, mais solidamente propositivas, acerca do que seja a Gerontologia e de suas possibilidades futuras.

\section{Consideraçõesfinais}

A Gerontologia, hoje, busca estabelecer-se como ciência do envel hecimento. Por tudo o que expusemos, consideramos que "Ciência" talvez não seja o mais preciso termo. Em sua concepção mais ampla, a Gerontologia é marcada por atividades de natureza técnica, como a Geriatria, e demais campos da saúde, como Enfermagem Geriátrica etc., o que inclui sensibilidades particulares, artes presentes no diagnóstico ena cura; da mesma forma, o Serviço Social. A Gerontologia relaciona-secom a pesquisa científica, com a produção de conhecimento por meio das ciências que têm o homem que envelhece como seu objeto empírico de estudo, como a Biologia do Envelhecimento (em desenvolvimento ao lado da Fisiologia, da Genética), a Economia ea Lingüística. E a Gerontologia inclui os saberes, quando estamos nesse domínio quase intangível das H umanidades na reflexão sobre o enveIhecimento deste ser único que pensa sobre si mesmo e sobre suas próprias representações.

Quanto ao fato de a Gerontologia ter por objeto 0 envelhecimento, entendemos que se trata de um projeto absolutamente ambicioso, que praticamente coincide com as Ciências H umanas e da Vida, quando se tematizam a juventude e o envelhecer, ainda muito distante do que se 
pratica e se estuda nos dias atuais. Hoje, parecenos, a Gerontologia encontra-se voltada para a velhice, enquanto que o processo de envelhecimento do ser humano corresponde apenas a uma pequena parcela de suas iniciativas.
0 que nos leva a afirmar que a Gerontologia, hoje, corresponde a um conjunto de ciências, técnicas e saberes voltados, principalmente, para esse ainda nebuloso domínio que é a velhice.

\section{Colaboradores}

SD Prado eJD Sayd participaram da concepção e desenvolvimento do artigo e da aprovação da versão a ser publicada.

\section{Referências}

1. Stengers I. Da racionalidade científica (capturas, eventos, interesses). In: Quem tem medo da ciência: ciências e poderes. São Paulo: Siciliano; 1990. p. $77-109$

2. Luz MT. Natural, racional, social: razão médica e racionalidade científica moderna. Rio de Janeiro: Campus; 1988.

3. Lopes A. Os desafios da gerontologia no Brasil. Campinas: Alínea; 2000.

4. Debert GG. A reinvenção da velhice. São Paulo: Edusp; 1999.

5. Sá JLM. Gerontologia e interdisciplinaridade: fundamentos epistemológicos. In: N eri AL, Debert GG. Velhice e sociedade. Campinas: Papirus; 1999.

6. Machado R. Ciência e saber: a trajetória da arqueologia de Foucault. Rio de Janeiro: Graal; 1988. p.9-10, 11 e 185.

7. Canguilhem G. O normal e o patológico. Rio de Janeiro: Forense-Universitária; 1982. p. 164, 166, 169 e 185.

8. Prado SD, Sayd JD. Gerontologia como campo do conhecimento científico: conceito, interesses e projeto político. Rev C S Col 2006; 11 (2):211-221.

9. Prado SD, Sayd JD. A pesquisa sobre envelhecimento humano no Brasil: pesquisadores, temas e tendências. Rev C S Col 2004; 9(3):763-772 .

10. Prado SD, Sayd JD. A pesquisa sobre envelhecimento humano no Brasil: grupos e linhas de pesquisa. Rev C S Col 2004; 9(1):57-67.

11. Foucault M. As palavras e as coisas: uma arqueologia das ciências humanas. São Paulo: Martins Fontes; 1990. p. 11, 362 e 384.

12. Prado SD. Envelhecimento, ciência e saber: a pesquisa sobre envelhecimento no Brasil [tese]. Rio de Janeiro: Instituto de Medicina Social da Universidade do Estado do Rio de Janeiro; 2004.

Artigo apresentado em 25/07/2005

Aprovado em 26/06/2006

Versão final apresentada em 8/08/2006 